Research Article

\title{
Effect of Cyclic Freezing-Thawing on the Shear Mechanical Characteristics of Nonpersistent Joints
}

\author{
Daxing Lei, ${ }^{1}$ Hang Lin $\mathbb{D},{ }^{1,2}$ Yifan Chen, ${ }^{1}$ Rihong Cao $\mathbb{D}^{1},{ }^{1}$ and Zhijie Wen $\mathbb{D}^{2}$ \\ ${ }^{1}$ School of Resources and Safety Engineering, Central South University, Changsha, Hunan 410083, China \\ ${ }^{2}$ State Key Laboratory of Mining Disaster Prevention and Control Co-founded by Shandong Province and \\ the Ministry of Science and Technology, Shandong University of Science and Technology, Qingdao 266590, China
}

Correspondence should be addressed to Hang Lin; linhangabc@126.com

Received 14 September 2019; Accepted 22 October 2019; Published 6 November 2019

Academic Editor: Paweł Kłosowski

Copyright (C) 2019 Daxing Lei et al. This is an open access article distributed under the Creative Commons Attribution License, which permits unrestricted use, distribution, and reproduction in any medium, provided the original work is properly cited.

\begin{abstract}
The effects of freezing-thawing cycles and persistency differences have a significant impact on the shear mechanical properties of joints. In this paper, a series of joints direct shear tests were performed on freezing-thawing treated joints to investigate the effect of freezing-thawing cycles and the persistency on the shear strength deterioration of joints. Shear strength and residual strength decrease with the freezing-thawing cycle increase and joint persistency increase. Shear strength damage mainly generates in the initial stage of the freezing-thawing cycle, and the shear strength decreases slightly in the late freezing-thawing cycle stage. The freeze-thaw cycle has a minimal effect on the shear strength of joints with low persistency, yet has a great effect on joints with high persistency. The damage of joint roughness caused by freezing-thawing cycles increases with joint persistency increases. When the joint persistency is constant, the shear strength parameter decreases with the freezing-thawing cycle at first and then tends to be stable. Cohesion is the dominant factor that controls shear strength. When freezing-thawing cycles are constant, the friction angle decreases slowly with persistency at first and then decreases rapidly, and the friction angle is the dominant factor that controls shear strength.
\end{abstract}

\section{Introduction}

The deterioration of rock mass mechanical properties caused by the freezing-thawing cycle is one of the main causes of geological disasters in cold regions [1-3]. Rock mass is a type of heterogeneous material, which contains many nonpersistent joints [4-10]. When the diurnal temperature is high, the water in joints will undergo periodic freezingthawing cycles. The periodic frost heaving force generated by freezing-thawing cycles causes the joint cracks to expand continuously, which will lead to be failure of the rock mass [11-13]. Many scholars have conducted numerous theoretical explorations and experimental research on freezingthawing mechanical characteristics at present [14], which can be categorized into two parts. The first part is the effect of freezing-thawing cycles on the mechanical properties of rock. For instance, Khanlari et al. [15] discussed the influence of the freezing-thawing cycle on physical parameters, such as uniaxial compressive strength, wave velocity, elastic modulus, and porosity of rocks. Martínez-Martínez et al. [16] and Ghobadi and Babazadeh [17] analyzed the relationship between rock characteristics, porosity, microfracture water pressure, and freezing-thawing damage of rocks. Momeni et al. [18] established the damage relationship between $P$ wave rate, tensile strength, and mechanical strength of freeze-thaw rocks according to the law of rock mechanical property deterioration under freezing-thawing cycles. Jin et al. [19] studied the variation law of cohesion and the friction angle of red sandstone with the freezing-thawing cycles based on the red sandstone freeze-thaw cycle test. The second part is the mechanism of freezing-thawing damage and rock degradation process according to microscopic characteristics and theoretical methods. For instance, Liu et al. [20] established a rock freeze-thaw damage model based on different mathematical models and verified the applicability of the proposed model through freeze-thaw experiments of tuff, 
limestone, and granite. Lu et al. [21] developed a damage constitutive model under freezing-thawing cycles by experiment of single-fracture sandstone. Fang et al. [22] proposed a damage statistical constitutive model on the basis of numerous freezing-thawing cycle experiments and provided the determination method of parameters.

The above research studies mainly focus on the freezingthawing cycle mechanical properties of rocks. However, the mechanical and safety characteristics of rock mass engineering are more affected by joints [23-27]. Therefore, the shear mechanical properties of joints are especially important [28-32]. In the freezing-thawing cycle environment, joints are more susceptible to freezing-thawing cycle and cause the shear strength of the rock mass to deteriorate, and these factors will lead to rock mass failure. Many scholars have conducted relevant investigations. Krautblatter et al. [33] analyzed the influence of the ice-containing state on slope stability after freezing in rock wall joints and explored the influence of ice slag on shear resistance of slope joints. $\mathrm{Mu}$ et al. [34] identified the variation law and damage model of freezing-thawing cycle on the shear strength for three types of jointed rocks by the shear tests of jointed rocks. Davies et al. [35] indicated that the shear test curve of jointed rock in the frozen state differs from the joint rock shear curve in the natural state. The above achievements primarily involve the persistent joints. However, rock masses contain nonpersistent joints with different persistency. Therefore, the shear mechanical properties of joints with different persistency under freezing-thawing cycles must be investigated. Consequently, low-temperature freeze-thaw container was used to simulate the freezing-thawing cycle environment, and joint specimens with different persistency were tested for shear mechanical properties under freezingthawing cycles. The effect of the freezing-thawing cycle on shear strength and shear strength parameters of joints was analyzed, which will provide a basis for the safety protection and disaster control of rock mass in cold regions.

\section{Specimen Preparation}

2.1. Specimen Material and Specimen Preparation. Due to the difficulty and high cost of prefabricating joints on real geotechnical materials [36-41], many scholars have chosen the method of testing a similar material model to investigate the effect of joints on the mechanical strength characteristics of the rock. In this paper, the rock-like material cement mortar was selected to produce the specimen. The ratio used for the mixture is $1: 1: 0.4$ of white cement: quartz sand: distilled water. Quartz sand particles of size $\leq 0.5 \mathrm{~mm}$ were selected to ensure the specimen homogeneity and joint smoothness. The length, width, and height of the steel mold are $100 \mathrm{~mm}, 100 \mathrm{~mm}$, and $100 \mathrm{~mm}$, the length of the acrylic sheet is $100 \mathrm{~mm}$, the thickness is $3 \mathrm{~mm}$, and the width is $20 \mathrm{~mm}, 30 \mathrm{~mm}$, and $40 \mathrm{~mm}$. These tools and materials were chosen to produce joint specimen (Figure 1). Furthermore, joint persistency was set as $0 \%$ (intact specimen), $20 \%, 30 \%$, and $40 \%$ to investigate the effect of persistency on the shear mechanical properties of joints under freezing-thawing cycles. The dimensions of prefabricated joints were
$70 \mathrm{~mm} \times 20 \mathrm{~mm} \times 3 \mathrm{~mm}, \quad 70 \mathrm{~mm} \times 30 \mathrm{~mm} \times 3 \mathrm{~mm}, \quad$ and $70 \mathrm{~mm} \times 40 \mathrm{~mm} \times 3 \mathrm{~mm}$. And the cement mortar was prepared according to the stated proportion and stirred evenly. After being poured into the mold, the acrylic sheet was inserted and fixed according to the joint size. Then, the acrylic sheets were removed and the specimens were demolded when the specimens were solidified completely. At last, these specimens were placed in constant temperature curing container for 28 days. Subsequently, the cube specimens with different persistency joints were completed (Figure 2).

2.2. Test Equipment and Scheme. The number of freezingthawing cycles $n$ and the joint persistency $\lambda$ were selected as test variables, and the effect test of the two factors was performed. The number of freezing-thawing cycles was set to $0,10,20,30$, and 40 times. The TDS-300 type automatic lowtemperature freezing-thawing container was used in this experiment (Figure 3). The freezing-thawing experiment process was divided into the following steps: (1) The jointed specimen was subjected to water saturation treatment, and joints were filled with pure water. (2) The saturated joint specimen was placed in the freezing-thawing container in sequence, and the freezing temperature was set to $-20^{\circ} \mathrm{C}$ for 4 hours, the melting temperature was set to $20^{\circ} \mathrm{C}$ for 4 hours, and the total number of cycles was 40 times, (3) The specimens were divided into five groups for $0,10,20,30$, and 40 times. The specimens were taken out when the freezingthawing cycles were completed. The preliminary preparation test revealed that test specimen and water in joints were completely frozen after freezing for $4 \mathrm{~h}$ at $-20^{\circ} \mathrm{C}$, and the joint specimen was completely thawed after being dissolved for $4 \mathrm{~h}$ at $20^{\circ} \mathrm{C}$, thereby indicating that choosing the freezing and dissolved time of $4 \mathrm{~h}$ in this test is reasonable.

The RYL-600 rock shear tester of the Changchun Chaoyang Instrument Factory was used for the shear experiment (Figure 4). In the direct shear process, the normal pressure was set at five levels: 0.5, 1.0, 1.5, 2.0, and 2.5 MPa. At the beginning of the test, the normal load was first applied to a predetermined level to maintain the normal force constant, and then the shear load was applied. The normal load was controlled by force, and the shear load was controlled by displacement. The normal force loading rate was $0.1 \mathrm{kN} / \mathrm{s}$, and the displacement loading rate in the shear direction was $0.5 \mathrm{~mm} / \mathrm{min}$. The samples subjected to different numbers freezing-thawing cycles were placed on the shearer until the target displacement was $10 \mathrm{~mm}$, and the shear stress-displacement curve was recorded. Figure 5 shows the schematic of sample shearing.

\section{Test Results and Analysis}

3.1. Effect of the Freezing-Thawing Cycles on the Shear StressShear Displacement Relationship. The joints shear surface before and after freezing-thawing cycles of the specimens are shown in Figure 6. The shear stress-shear displacement relationship of joint specimens for freezing-thawing cycles 0 , $10,20,30$, and 40 times at the joint persistency of $30 \%$ is 


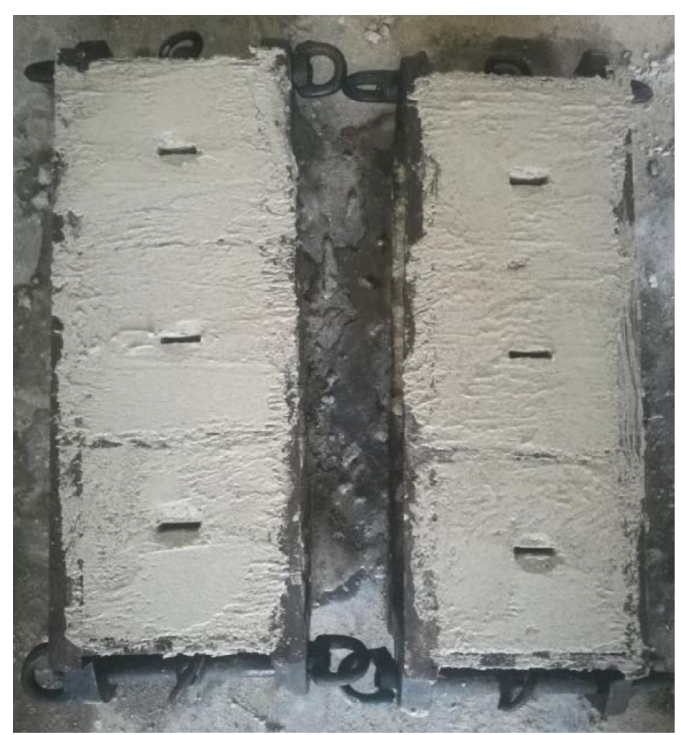

(a)

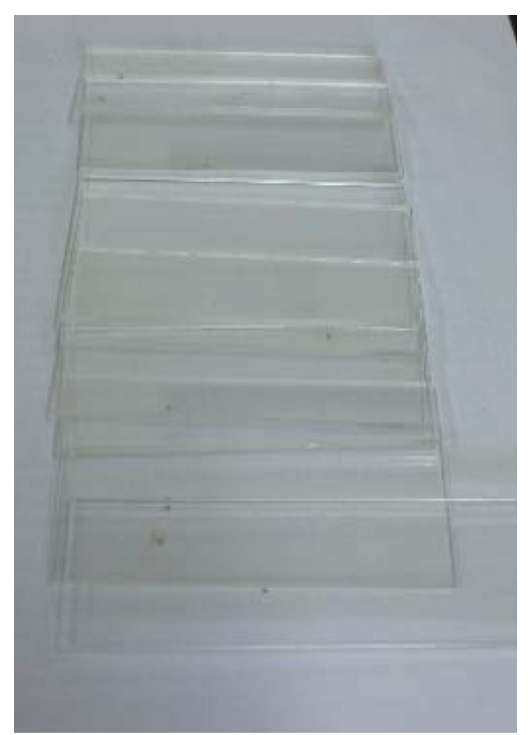

(b)

Figure 1: Specimen and test equipment. (a) Specimen diagram and (b) acrylic sheet.

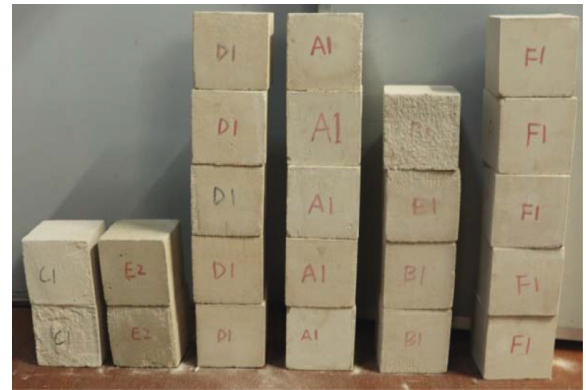

(a)

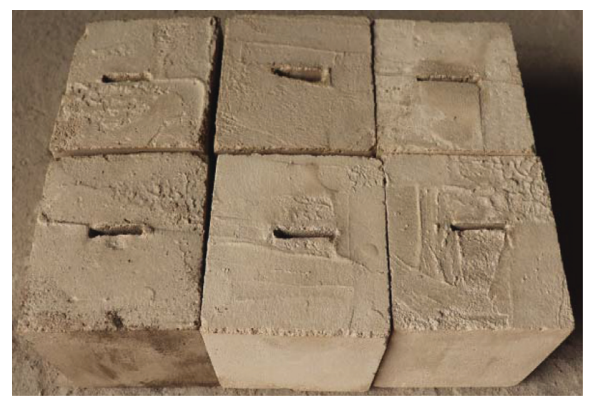

(c)

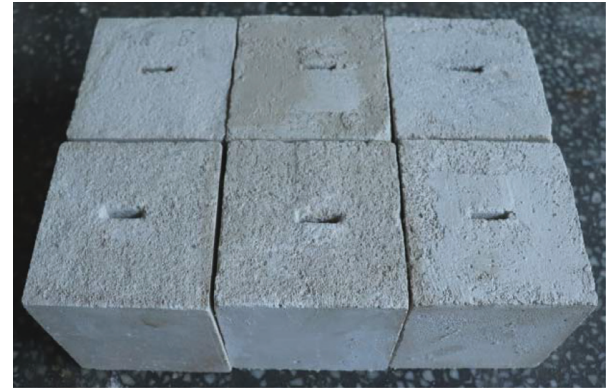

(b)

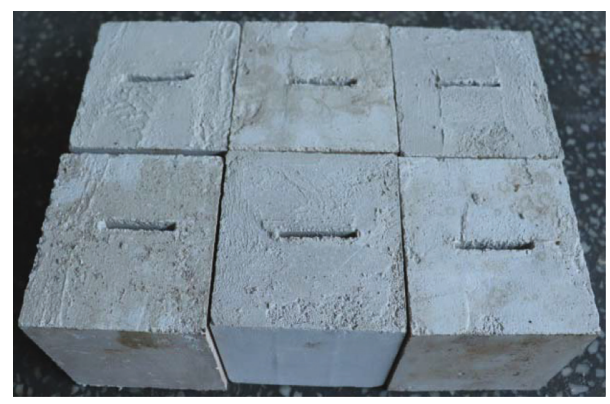

(d)

FIgURE 2: Joint specimens with different persistency. (a) Intact specimens, (b) $\lambda=30 \%$, (c) $\lambda=30 \%$, and (d) $\lambda=40 \%$.

displayed in Figure 7. The regularity of variation in the shear stress on the specimen with the increasing shear displacement can be summarized into three stages. The first stage is characterized by an increasing shear stress. At this stage, the shear stress on the shearing surface of each specimen slightly increases as the shear displacement increases. Subsequently, the slope of the curve begins to build, and the shear stress increases to the peak shear strength at a faster rate. The shear resistance on the joint is not fully functional when the shear displacement is relatively slight, and the curve ascends slowly. As the shear displacement increases, the cohesion and the friction angle of the joint begin to play their roles, and the shear stress starts to rise steadily until the peak strength. The second stage is the stress decrease phase. When the shear strength reaches the peak, the specimen undergoes shear failure, and the shear strength on the joint decreases rapidly, with a stress drop on the curve. As the shear displacement continues to increase, the specimen is completely sheared. The third stage is the residual stress section. At this stage, the shear strength of the joint tends to be stable with 


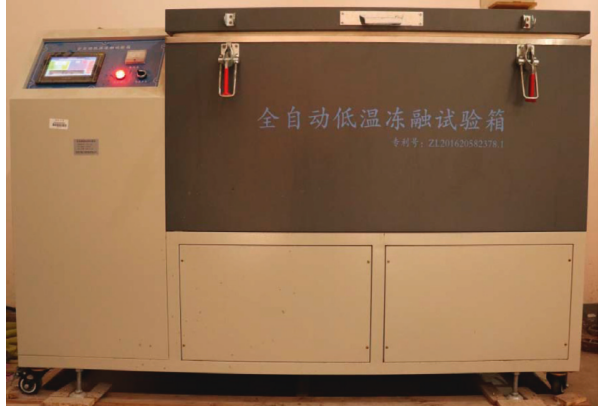

FIGURE 3: TDS-300 type automatic low-temperature freezingthawing container.

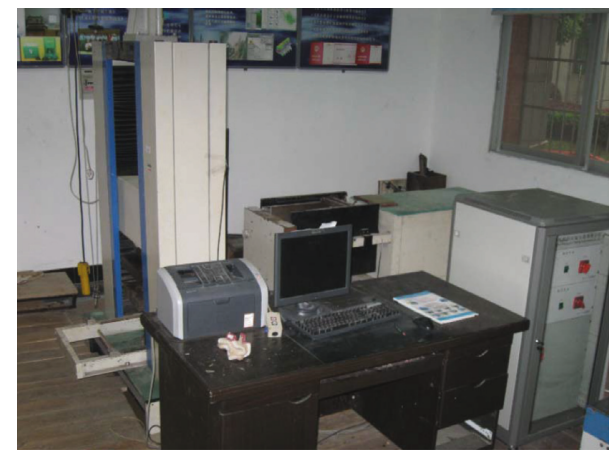

FiguRe 4: RYL-600 rock shear tester.

only the residual shear strength remaining, and the residual shear strength of the specimen slowly decreases with the increase in shear displacement. As the shearing advances, the shearing surface becomes smoother under friction, and the residual shear strength decreases.

The effect of different numbers of freezing-thawing cycles on shear mechanical behavior is compared (Figure 8). The shear strength of the unfrozen-thawed specimens was significantly greater than that after the freezing-thawing process. The structure of the unfrozen-thawed specimen is relatively complete with fewer internal cracks, whereas the frozen-thawed specimen gradually produces macroscopic crack under the frost heaving force. Such cracking leads to damage of the sample and causes a decrease in strength. However, the peak shear strength after 10,20,30, and 40 freezing-thawing cycles showed little difference. Thus, the joint shear strength damage mainly generates in the initial stage of the freezing-thawing cycle, and the freezing-thawing damage changes from the macrolevel to the microlevel due to the gradual migration loss of water in the late stage. Consequently, the decreasing range of shear strength in the late stage is small. When the normal stress is 0.5 and $1 \mathrm{MPa}$, the peak shear displacement of the unfrozen-thawed specimens is larger, and when the normal stress is 2 and $2.5 \mathrm{MPa}$, the peak shear displacement of the unfrozen-thawed samples is close to that of the frozen-thawed specimens. When the normal stress is small, the crack generated by the specimen under the action of frost heaving after being frozen-thawed is not completely closed, and shear damage is more likely to generate under the shearing force. However, when the normal stress is large, the joint fissure and cracks are

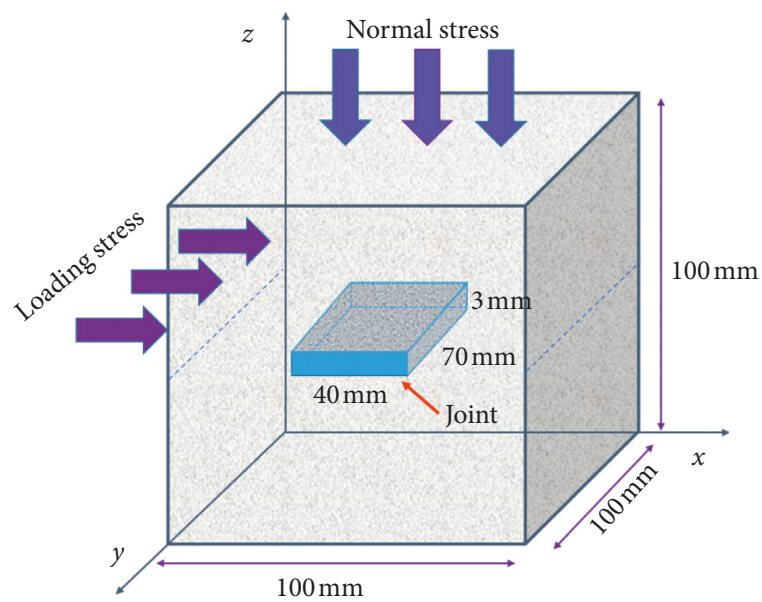

(a)

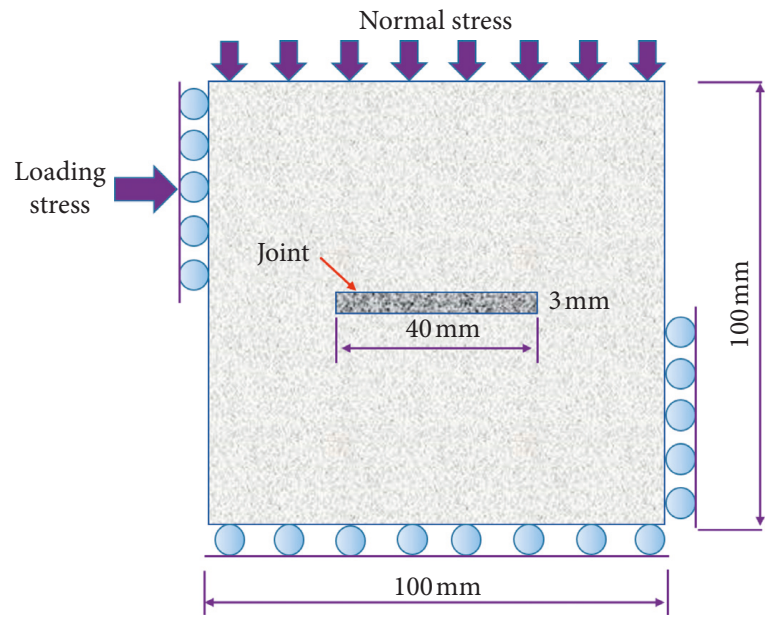

(b)

Figure 5: $\lambda=40 \%$ specimen shear diagram. (a) Joint specimen stereogram and (b) joint specimen plan.

substantially closed. Therefore, the displacement of the shear failure of the specimen before and after being frozen-thawed is similar. The residual strength also decreases with the freezing-thawing cycle increase. In addition, the residual strength is provided by the mechanical interaction and friction resistance of the failure surface. Therefore, freezingthawing cycles will cause deterioration of the friction coefficient of the joint.

3.2. Effect of Joint Persistency on the Shear Stress-Shear Displacement Relationship. The normal stress of $1.0 \mathrm{MPa}$ was set as an example to explore the effect of different joint persistency values on the direct shear mechanical properties of freezing-thawing specimens. The corresponding shear stress and displacement curves were compared (Figure 9). Shear strength increases with joint persistency decrease. Rock bridge places a constraint on shear displacement. The shear strength of the intact specimen and the joint specimen is similar under unfrozen-thawed cycles. Meanwhile, the shear strength of the intact specimen is significantly larger than that of the joint specimen after being frozen-thawed. At 


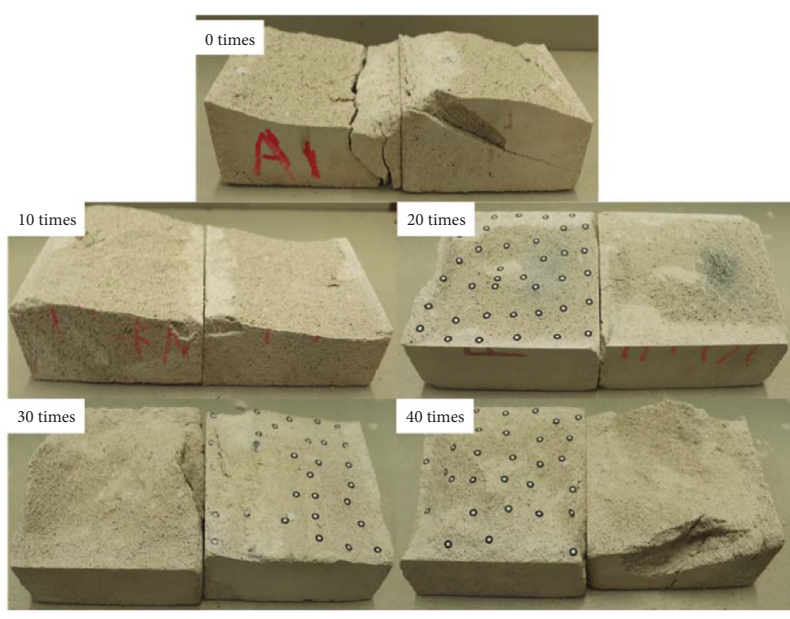

(a)

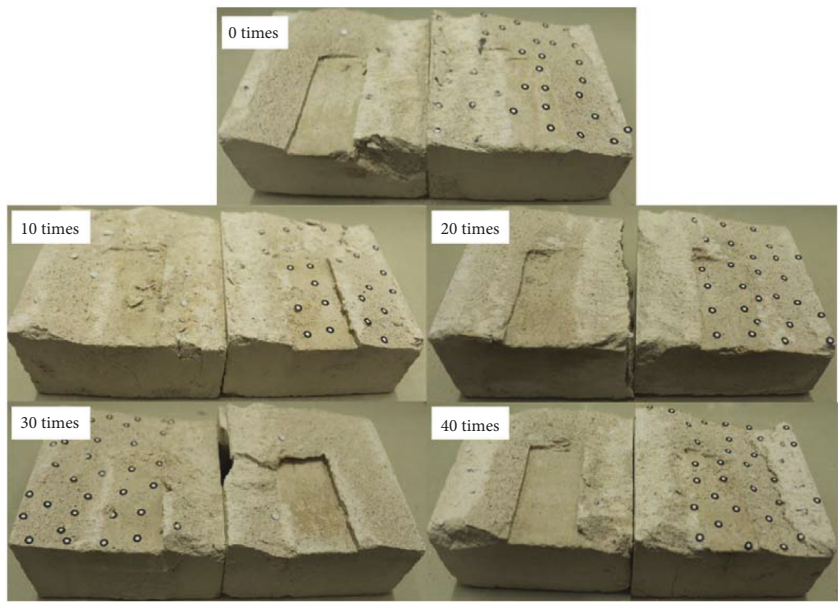

(c)

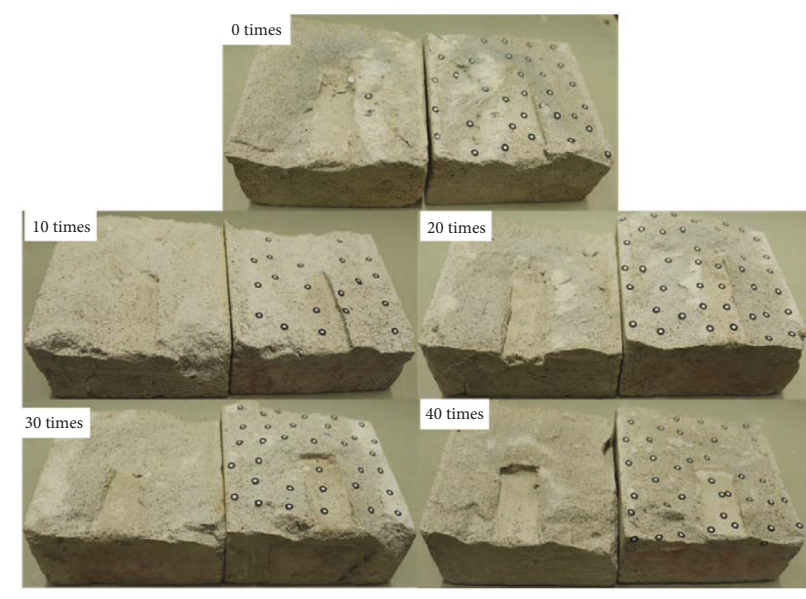

(b)

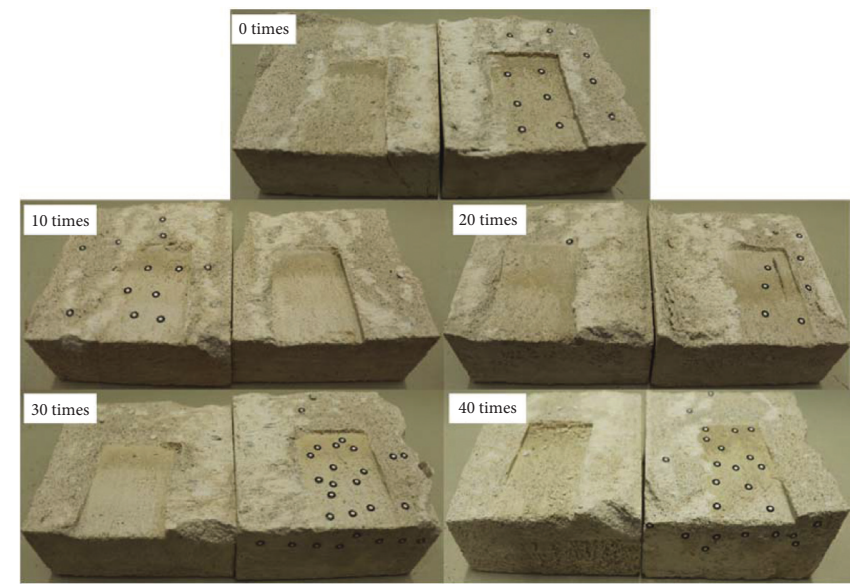

(d)

Figure 6: The shear specimens after different freezing-thawing cycles. (a) $\lambda=0 \%$ shear specimen after freezing-thawing cycles, (b) $\lambda=20 \%$ shear specimen after freezing-thawing cycles, (c) $\lambda=30 \%$ shear specimen after freezing-thawing cycles, and (d) $\lambda=40 \%$ shear specimen after freezing-thawing cycles.

the initial loading stage, the shear displacement was small and the linear segments were obvious. Subsequently, the joint surface begins to slide after the yield phase is reached. The larger the area of the rock bridge, the more the failure mode tends to cause intact specimen shear failure, and the more obvious the brittle failure feature. In addition, the failure surface of the joint is smooth, and the failure surface of the rock bridge is rough. Therefore, the lower joint persistency leads to a larger residual strength of the specimen under the same normal load.

The normal stress of 1.0 MPa was set as an example to explore the effect of freezing-thawing cycles on the direct shear mechanical properties of different persistency specimens. The corresponding shear stress and displacement curves were compared (Figure 10). The decrease of shear strength from the increase of the intact sample with freezingthawing cycles is small. When joint persistency is $20 \%, 30 \%$, and $40 \%$, the joint shear strength decreases sharply with the freezing-thawing cycle increase, thereby indicating that freeze-thaw cycles have less effect on the shear strength of joint specimens with low persistency. However, it has a greater effect on joint specimens with large persistency. The peak shear displacement of the joint specimens after being frozen-thawed is less than that before being frozen-thawed. Moreover, the peak displacement difference before and after being frozen-thawed increases with the joint persistency increase. Therefore, it will have smaller shear displacement corresponding to the peak shear strength of the joint specimen with the freezing-thawing cycle increase. When the joint persistency is 0 and $20 \%$, the shear residual strength of the specimens with different frozen-thawed cycles is close, but when the joint persistency is $30 \%$ and $40 \%$, the residual strength before being frozen-thawed is greater than that after being frozen-thawed. At the same time, the residual strength after being frozen-thawed is relatively constant. Therefore, the residual strength difference before and after being frozen-thawed generally increases with the joint persistency increase, thereby indicating that the freezing-thawing cycle has a significant effect on the roughness of joints. The specific effect is that the freezing-thawing cycle will promote roughness deterioration when the joint persistency increases. 

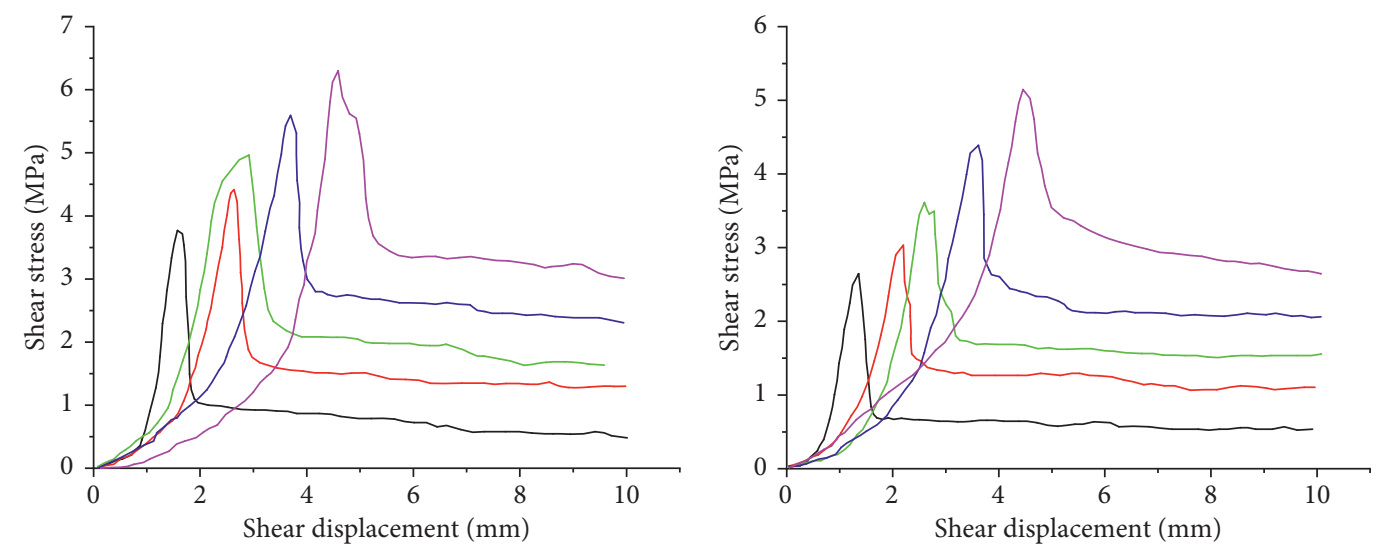

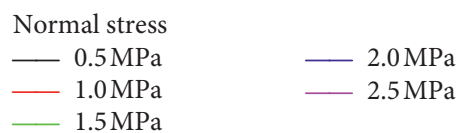

(a)

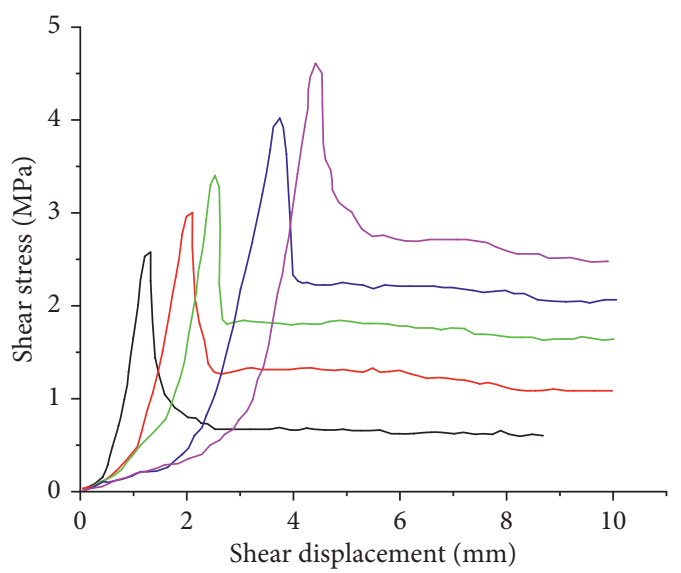

Normal stress

Normal stress
$-0.5 \mathrm{MPa}$

$-1.0 \mathrm{MPa}$

$-1.5 \mathrm{MPa}$

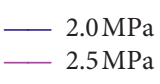

$-2.5 \mathrm{MPa}$
Normal stress

$-0.5 \mathrm{MPa}$
$-1.0 \mathrm{MPa}$

$-1.5 \mathrm{MPa}$

(b)

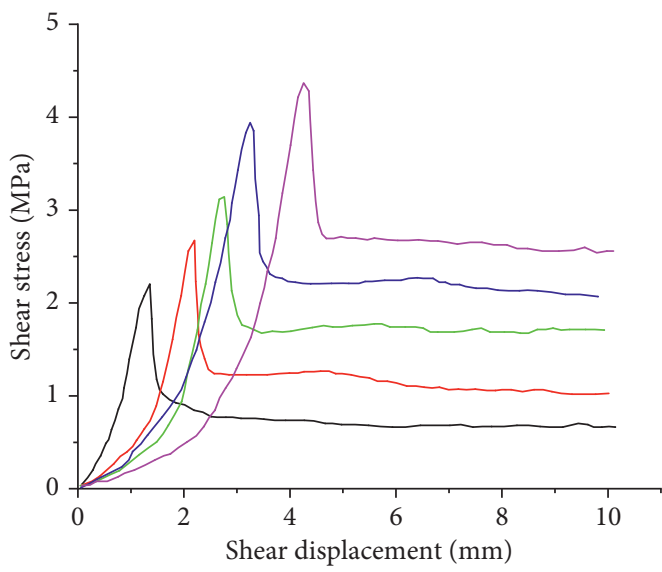

Normal stress

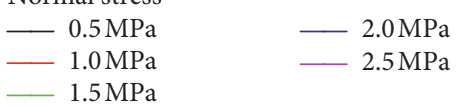

(c)

(d)

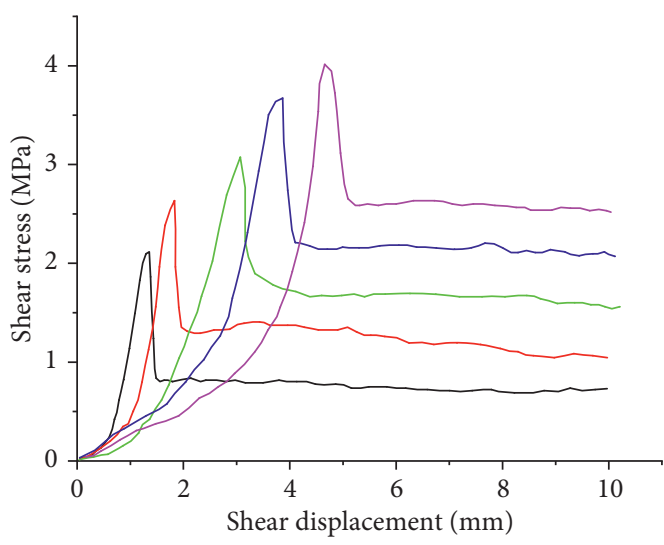

Normal stress

$0.5 \mathrm{MPa}$
$-1.0 \mathrm{MPa}$

$-2.0 \mathrm{MPa}$

$-1.5 \mathrm{MPa}$

(e)

Figure 7: Relationship between shear stress and shear displacement of $\lambda=30 \%$ specimen with different normal stresses. Freeze-thaw cycles (a) 0 times, (b) 10 times, (c) 20 times, (d) 30 times, and (e) 40 times. 


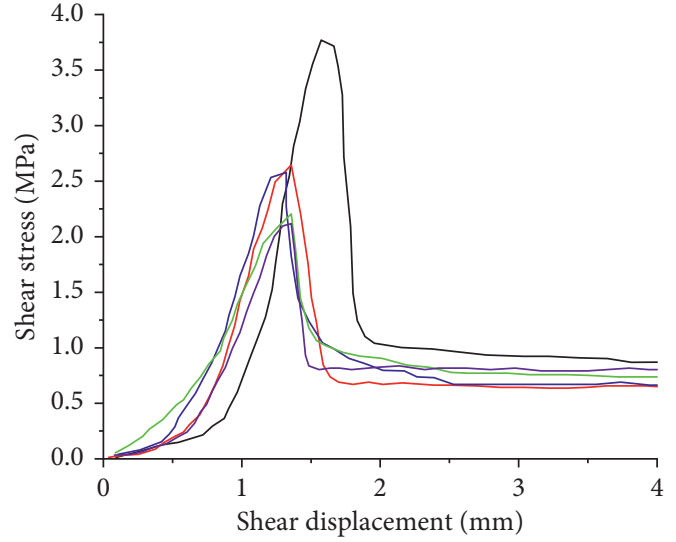

Freeze-thaw cycles

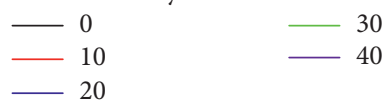

(a)

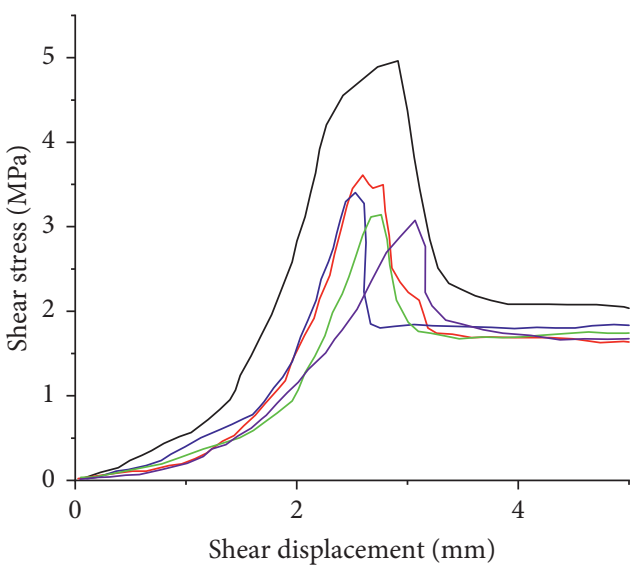

Freeze-thaw cycles

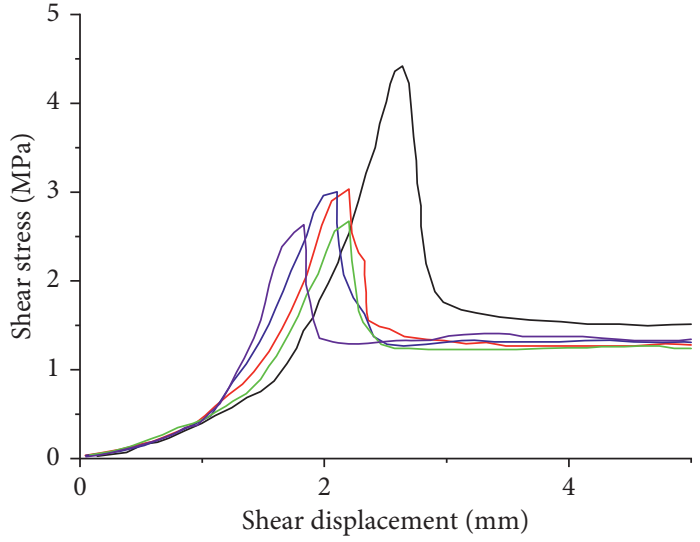

Freeze-thaw cycles

$\begin{array}{ll}- & 0 \\ - & 10\end{array}$

$-20$

30
40

(b)

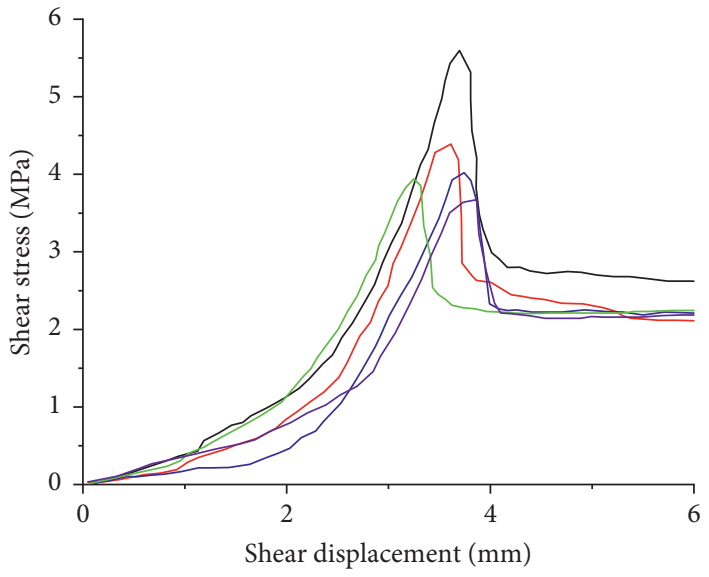

Freeze-thaw cycles

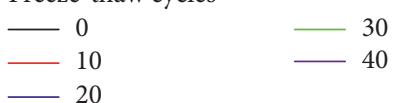

(d)

(c)

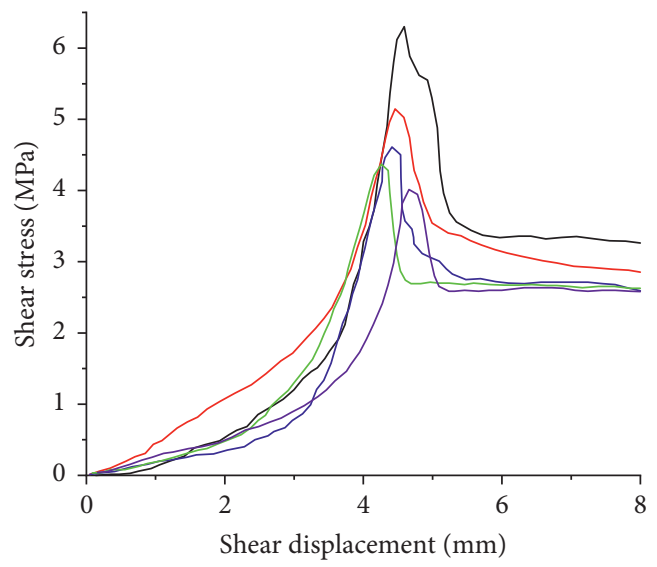

Freeze-thaw cycles

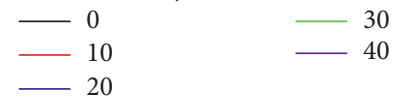

(e)

FIGURE 8: Relationship between shear stress and shear displacement of specimens with different freezing-thawing cycles under normal stress. Normal stress (a) $0.5 \mathrm{MPa}$, (b) $1.0 \mathrm{MPa}$, (c) $1.5 \mathrm{MPa}$, (d) $2.0 \mathrm{MPa}$, and (e) $2.5 \mathrm{MPa}$. 

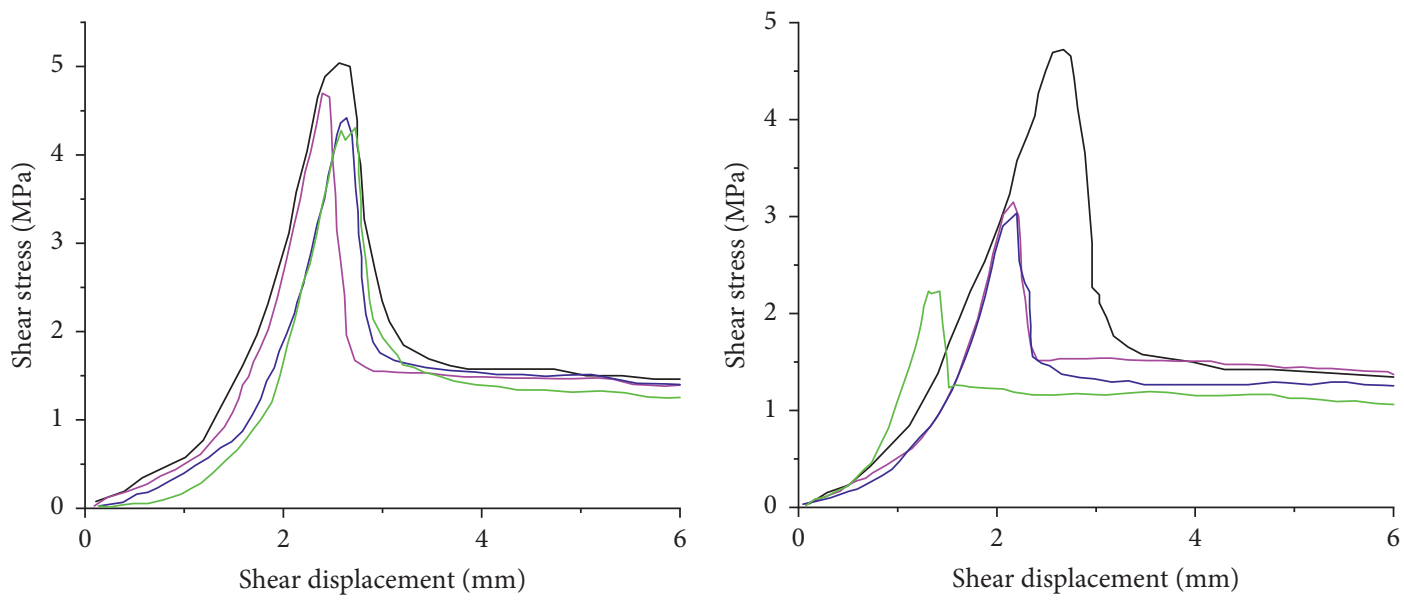

Persistency
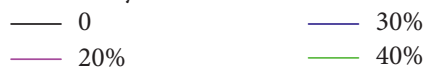

Persistency

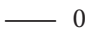

$-30 \%$

$-20 \%$

$40 \%$

(a)

(b)
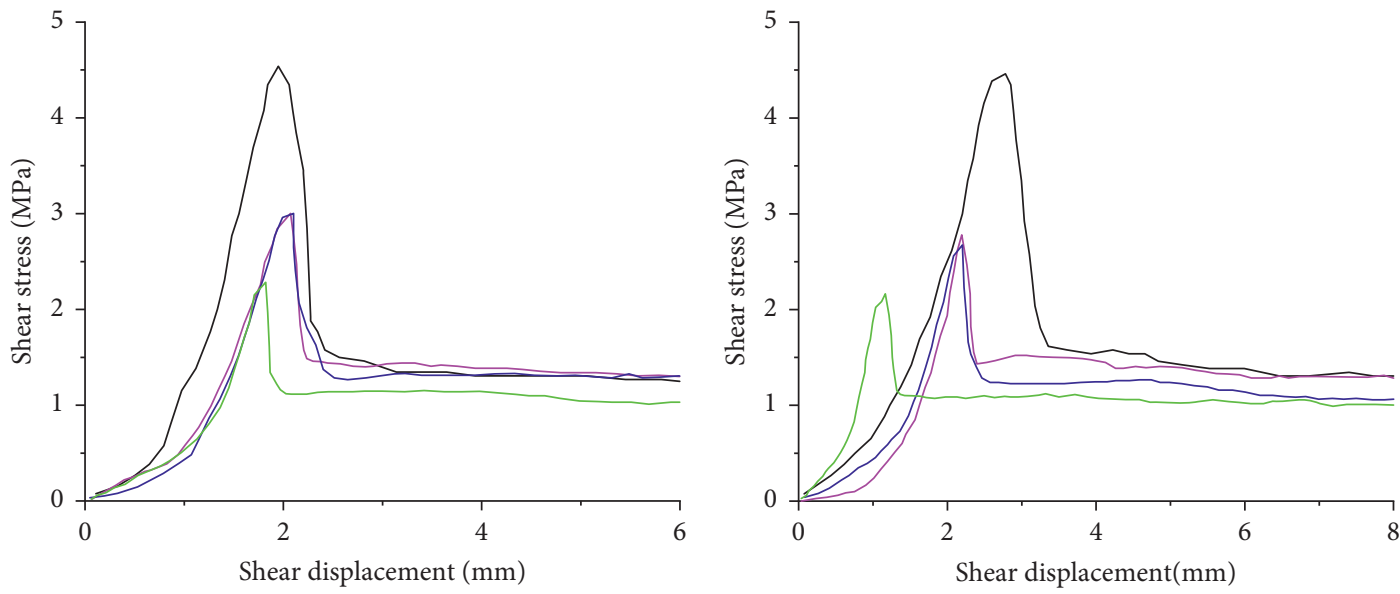

Persistency

$\begin{array}{ll}-0 & -30 \% \\ -20 \% & -40 \%\end{array}$

Persistency

$\begin{array}{ll}- & -\quad 30 \% \\ -20 \% & -\quad 40 \%\end{array}$

(c)

(d)
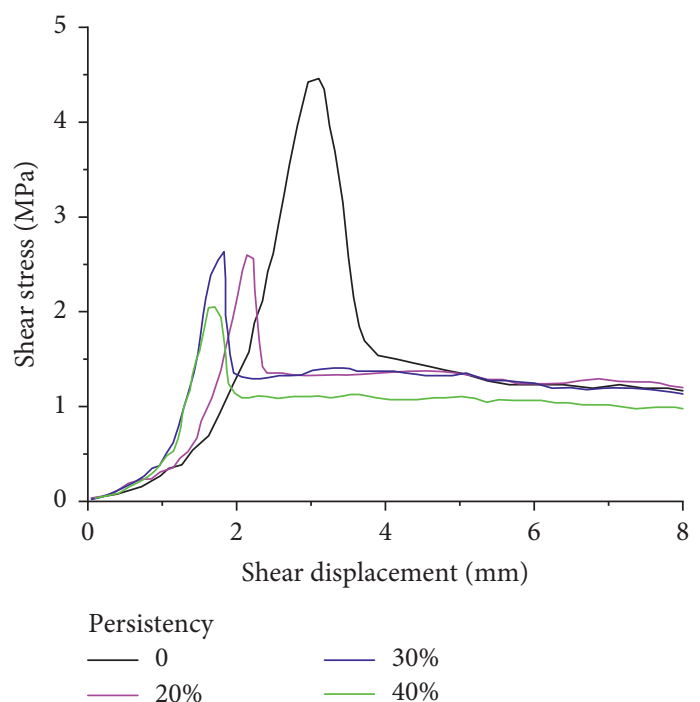

(e)

FIGURE 9: Relationship between shear stress and shear displacement of freezing-thawing specimens with different persistency. Freeze-thaw cycles (a) 0 times, (b) 10 times, (c) 20 times, (d) 30 times, and (e) 40 times. 


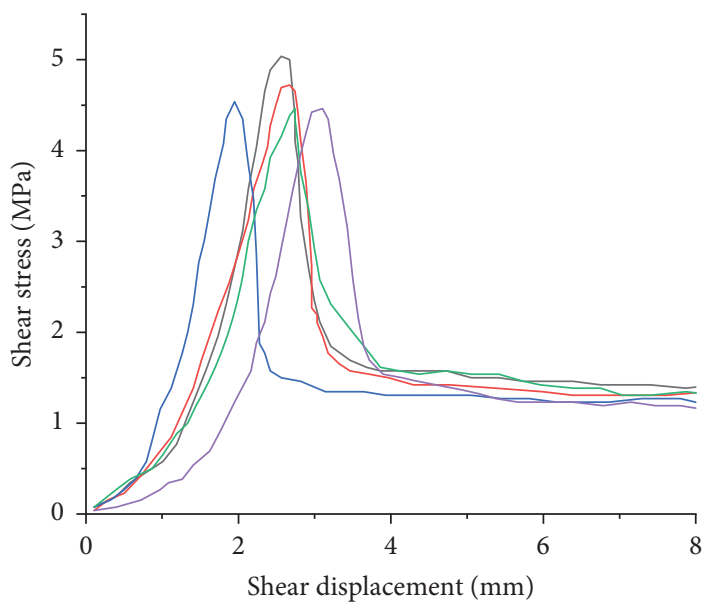

Freeze-thaw cycles

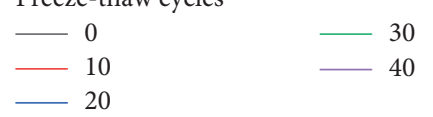

(a)

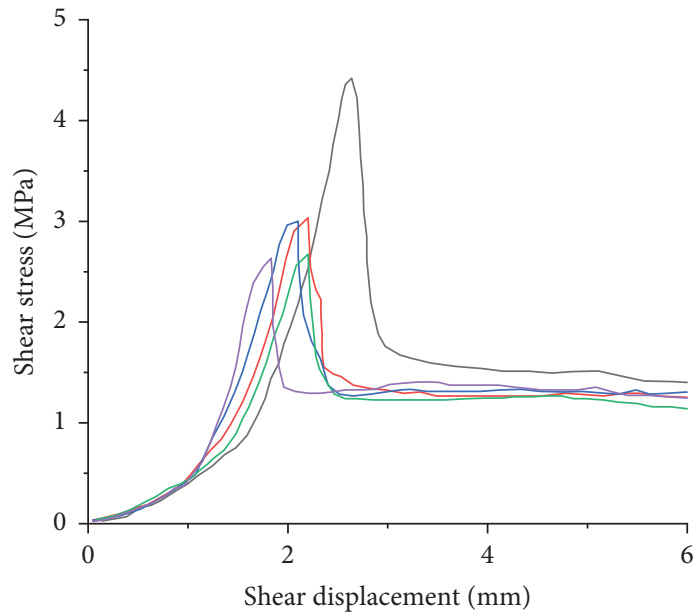

Freeze-thaw cycles

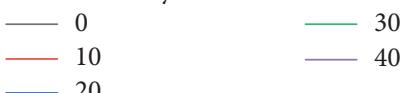

(c)

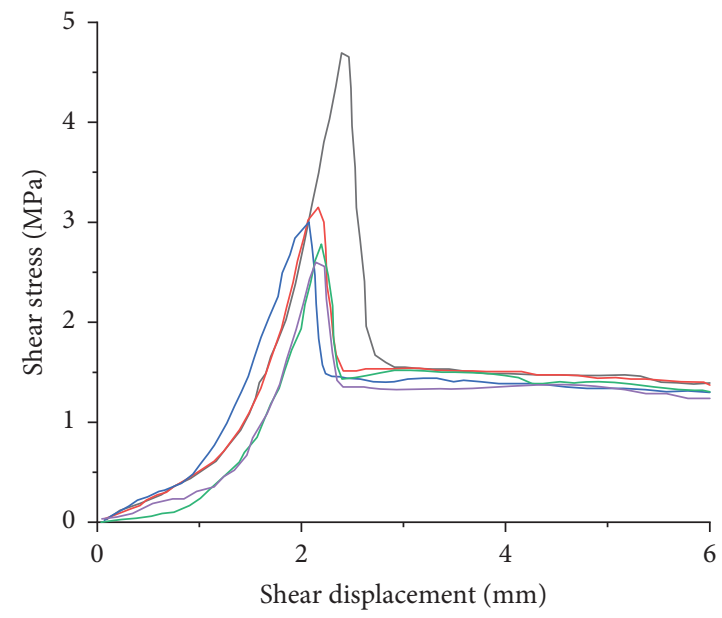

Freeze-thaw cycles

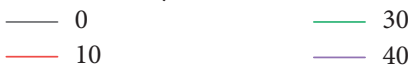

(b)

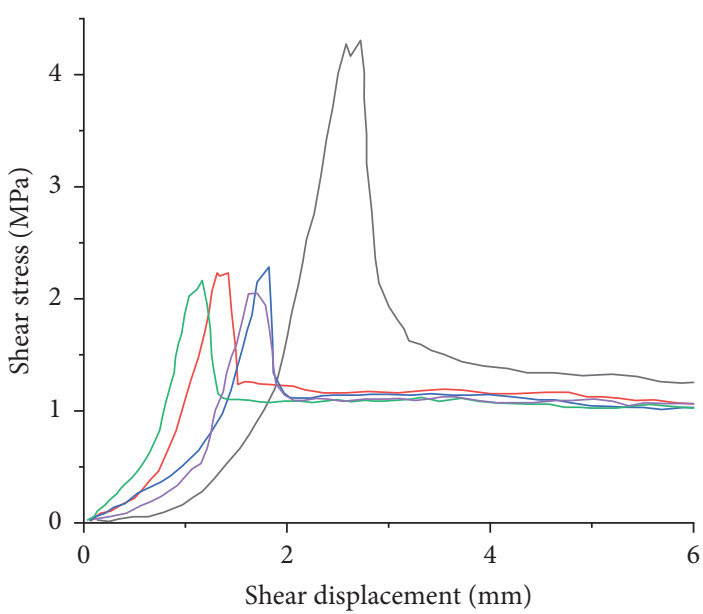

Freeze-thaw cycles

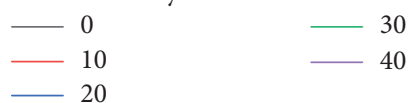

(d)

Figure 10: Relationship between shear stress and shear displacement of different freezing-thawing cycles under different persistency. (a) $\lambda=0$, (b) $\lambda=20 \%$, (c) $\lambda=30 \%$, and (d) $\lambda=40 \%$.

The effects of persistency and the freezing-thawing cycle on normal stress joints at all levels were analyzed (Figure 11). The shear strength of intact samples increases linearly with the normal stress increase under the freezing-thawing cycle. However, the difference in peak shear strength before and after being frozen-thawed under normal stress at all levels is large when the joint persistency is $20 \%, 30 \%$, and $40 \%$. Therefore, the joint will change the regularity of the effect of freezing-thawing cycle on the peak shear strength. The specific effect accelerates deterioration of the peak shear strength. When the joint persistency is $20 \%$, the peak shear strength of freezing-thawing cycles of 10 and 20 times is almost the same, and the peak shear strength has the same trend with normal stress increase. Meanwhile, the peak shear strengths of freezing-thawing cycles of 30 and 40 times show the same trend. Results indicate that the strength deterioration of the joint by the freezing-thawing cycle is small at the stages with 10 to 20 cycles and 30 to 40 cycles. Furthermore, when the joint persistency is $40 \%$, the peak shear strength difference is large at the initial stage. And the peak shear strength decreases slightly in 10 times (excluding 10 times) to 40 times stage, indicating that freezing-thawing cycles deteriorate shear strength significantly at the initial stage, and the damage to joints by the freezing-thawing process is relatively small when the freezing-thawing cycles are more than 10 times. 


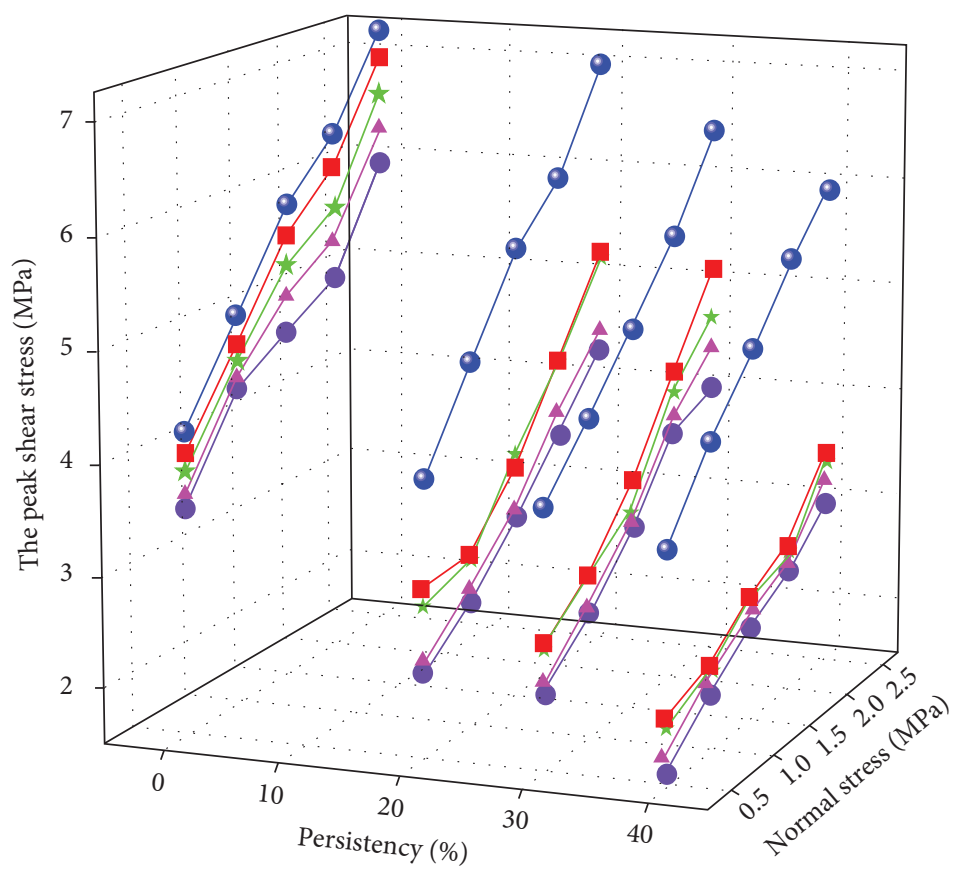

Freeze-thaw cycles
$-0-0$
$\rightarrow-10$
$\rightarrow \star 20$

FIGURE 11: Relationship between joint peak shear stress and persistency and normal stress under freezing-thawing cycles.

3.3. Effect of Freezing-Thawing Cycles and Joint Persistency on the Shear Mechanical Parameters. The shear stress-displacement curve was recorded. In addition, the relationship between shear stress and normal stress is plotted by the least squares method, as shown in Figure 11. Subsequently, the Mohr-Coulomb criterion was employed to calculate the shear strength parameters of joint specimens. And the cohesion $c$ and the friction angle $\varphi$ of joints with different persistency and numbers of freeze-thaw cycles are shown in Table 1.

The variation of shear strength parameters with freezing-thawing cycles was analyzed (Figure 12), and the cohesion and friction angle showed similar variation trend with the freezing-thawing cycle increase. The cohesion and friction angle of the intact sample decreased linearly with the freezing-thawing cycle increase. However, the shear strength parameters of joint specimens decrease exponentially with the freezing-thawing cycle increase. For instance, compared with the 0 time of freezingthawing cycle, in $\lambda=40 \%$ specimens, the joint cohesion of $10,20,30$, and 40 cycles decreased by $48.17 \%, 52.65 \%$, $60.67 \%, 66.47 \%$, and the friction angle decreased by $27.40 \%, 31.23 \%, 32.65 \%$, and $33.80 \%$. Furthermore, the similar variation law was exhibited by other joint persistency specimens. Therefore, shear strength parameter has the largest decrease by freezing-thawing cycle at the initial stage, and then the shear strength parameters slowly decrease and gradually stabilize in the later stage. In addition, the cohesion variation is larger than the friction angle with the freezing-thawing cycle increase, and such
TABLE 1: Shear strength parameters of joint specimens before and after freezing-thawing cycles.

\begin{tabular}{|c|c|c|c|}
\hline \multirow[t]{2}{*}{$\lambda(\%)$} & \multirow[t]{2}{*}{ Freeze-thaw cycles $(n)$} & \multicolumn{2}{|c|}{$\begin{array}{c}\text { Shear strength } \\
\text { parameters }\end{array}$} \\
\hline & & $c(\mathrm{MPa})$ & $\varphi\left({ }^{\circ}\right)$ \\
\hline \multirow{5}{*}{0} & 0 & 3.20 & 58.5 \\
\hline & 10 & 3.16 & 57.1 \\
\hline & 20 & 3.11 & 56.7 \\
\hline & 30 & 3.10 & 56.1 \\
\hline & 40 & 3.06 & 55.3 \\
\hline \multirow{5}{*}{20} & 0 & 3.12 & 55.6 \\
\hline & 10 & 2.01 & 50.6 \\
\hline & 20 & 1.93 & 49.1 \\
\hline & 30 & 1.68 & 46.9 \\
\hline & 40 & 1.66 & 46.3 \\
\hline \multirow{5}{*}{30} & 0 & 3.04 & 52.2 \\
\hline & 10 & 1.84 & 49.3 \\
\hline & 20 & 1.73 & 46.8 \\
\hline & 30 & 1.61 & 44.2 \\
\hline & 40 & 1.60 & 43.9 \\
\hline \multirow{5}{*}{40} & 0 & 3.01 & 50.2 \\
\hline & 10 & 1.56 & 36.5 \\
\hline & 20 & 1.49 & 35.1 \\
\hline & 30 & 1.37 & 34.6 \\
\hline & 40 & 1.29 & 34.2 \\
\hline
\end{tabular}

variation is more sensitive to freezing-thawing cycles. Therefore, the variation of cohesion is significant under freezing-thawing cycle when the persistency is constant, 

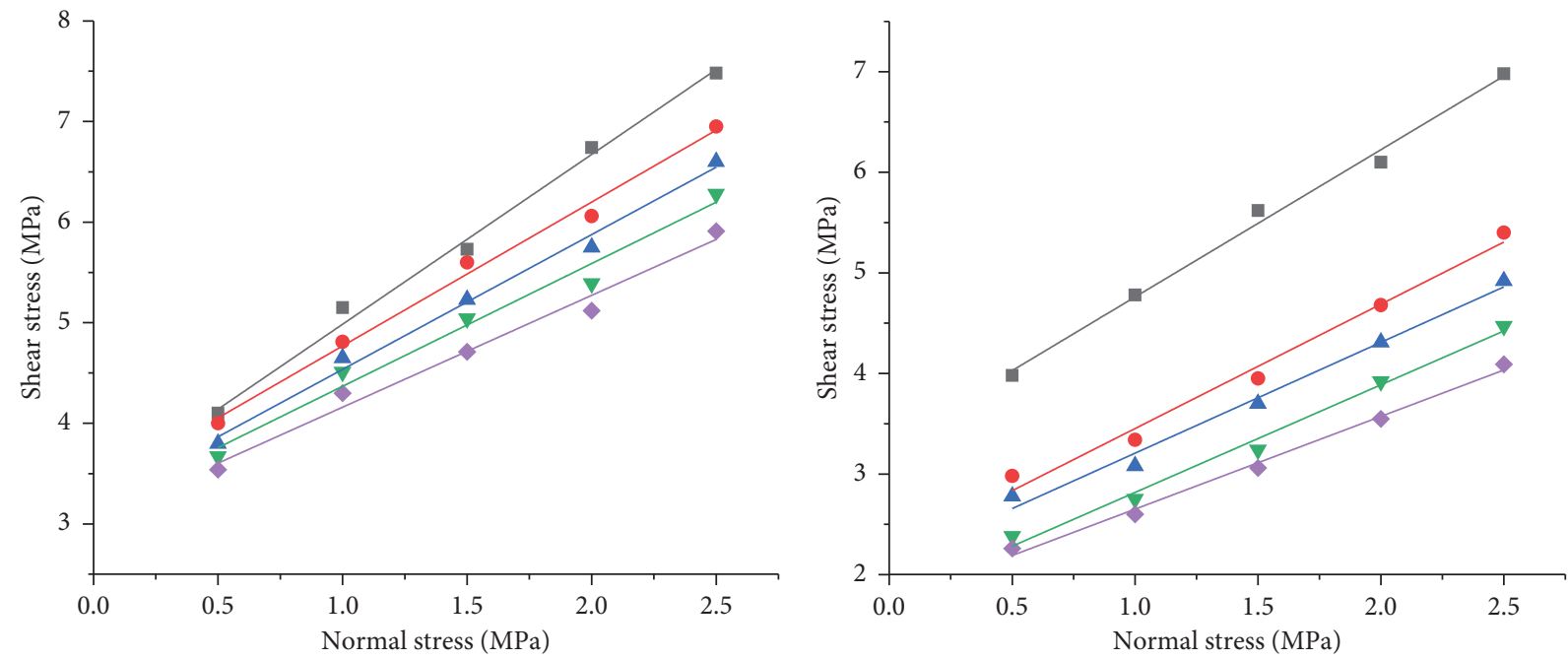

Freeze-thaw cycles

- 0 (test data)

_ 0 (fitting curve)

- 10 (test data)

- 10 (fitting curve)

- 20 (test data)

_ 20 (fitting curve)

$\checkmark 30$ (test data)

- 30 (fitting curve)

- 40 (test data)

_ 40 (fitting curve)

(a)

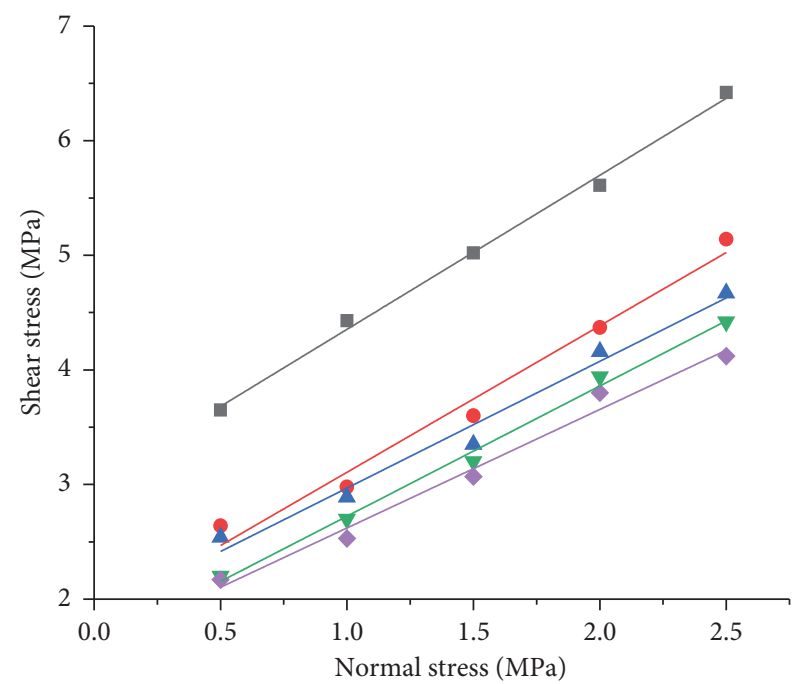

Freeze-thaw cycles

- 0 (test data)

- 10 (test data)

- 20 (test data)

₹ 30 (test data)

- 40 (test data)

(c)

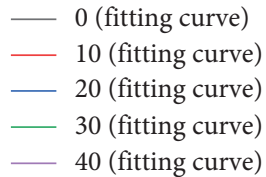

FIGURE 12: The relationship between peak shear stress and normal stress under different freezing-thawing cycles. (a) $\lambda=0 \%$ specimen, (b) $\lambda=20 \%$ specimen, (c) $\lambda=30 \%$ specimen, and (d) $\lambda=40 \%$ specimen.

and cohesion is the dominant factor that controls shear strength.

The variation of shear strength parameters with joint persistency was analyzed (Figures 13 and 14). The cohesion and friction angle of the intact sample decreased linearly with joint persistency increase, and the decrease of the friction angle is more significant. However, the shear strength parameters of the four groups of specimens after being frozen-thawed show different exponential decreasing trends with the freezing-thawing cycle increase. For specimens with 40 freezing-thawing cycles, compared with the intact specimen, the joint cohesion with persistency of $20 \%$, 

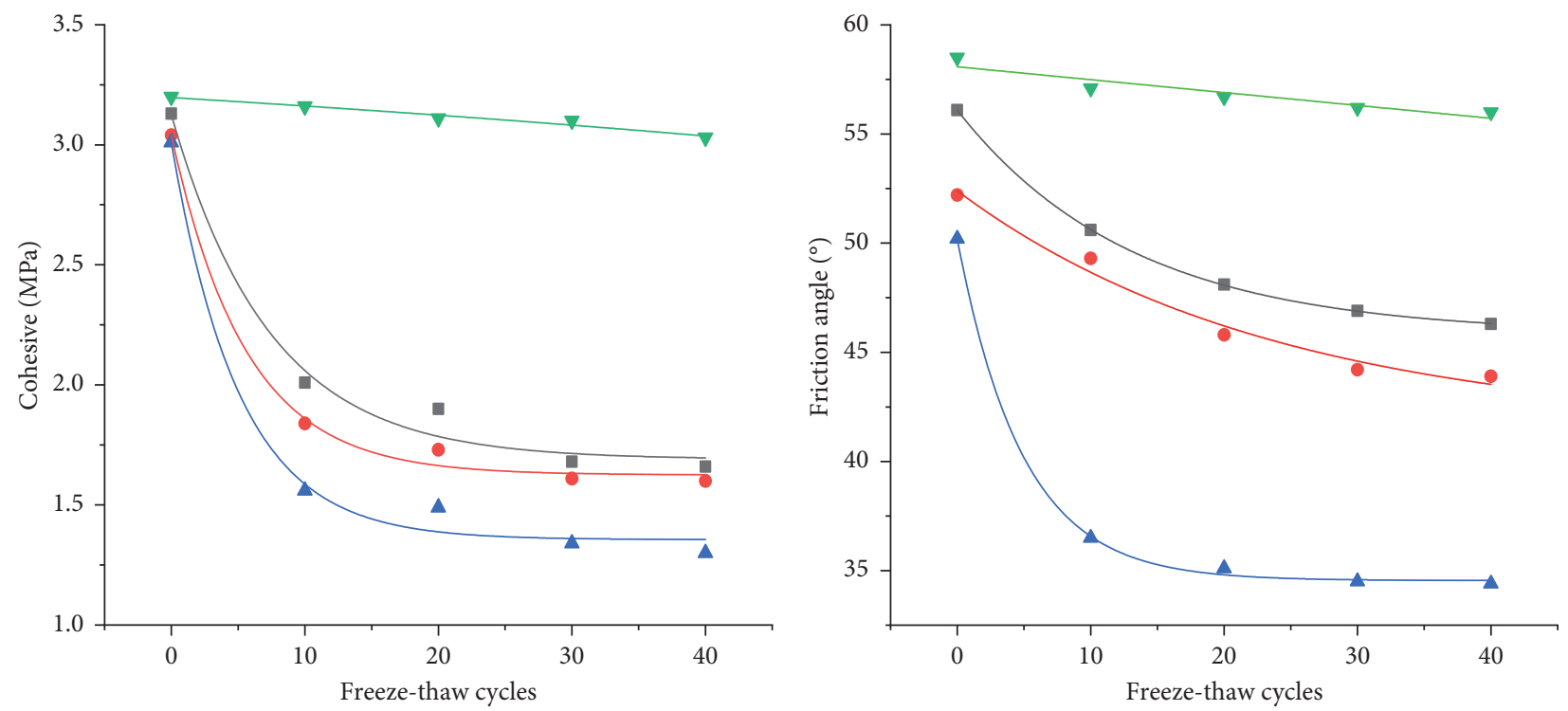

Persistency

$\checkmark 0$ (test data)

- $20 \%$ (test data)

0 (fitting curve)

- $30 \%$ (test data)

_ $20 \%$ (fitting curve)

- $40 \%$ (test data)

$30 \%$ (fitting curve)

$40 \%$ (fitting curve)

(a)

Persistency

$\nabla 0$ (test data)

- $20 \%$ (test data)

- $30 \%$ (test data)

- $40 \%$ (test data)

thaw cycles

FIGURE 13: Variation law of shear strength parameters of joint specimens with freezing-thawing cycles: (a) variation law of cohesive and (b) variation law of friction angle.

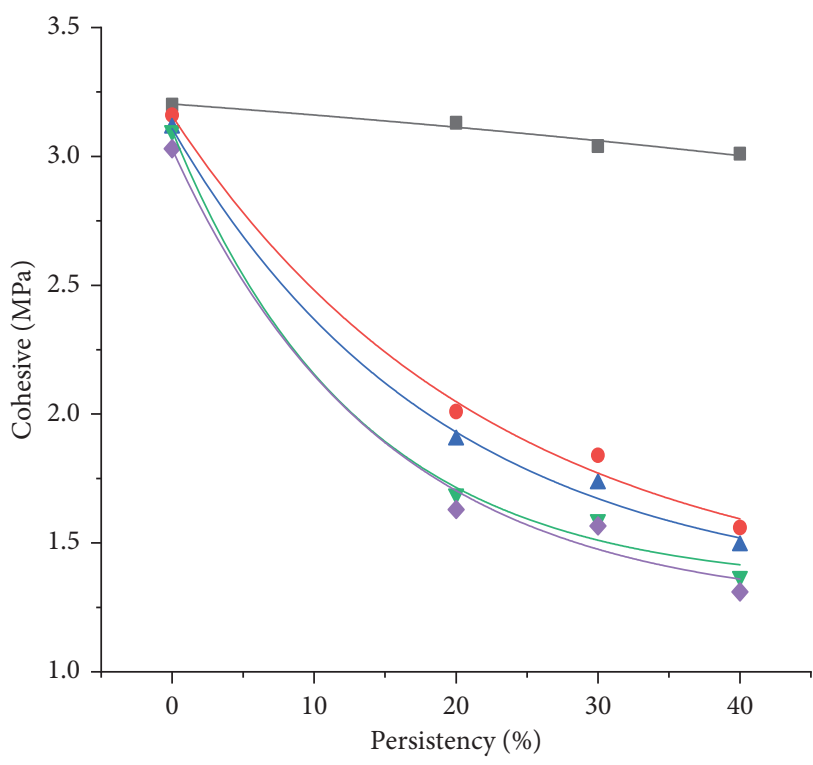

Freeze-thaw cycles

- 0 (test data)

- 10 (test data)

- 20 (test data)

V 30 (test data)

- 40 (test data)

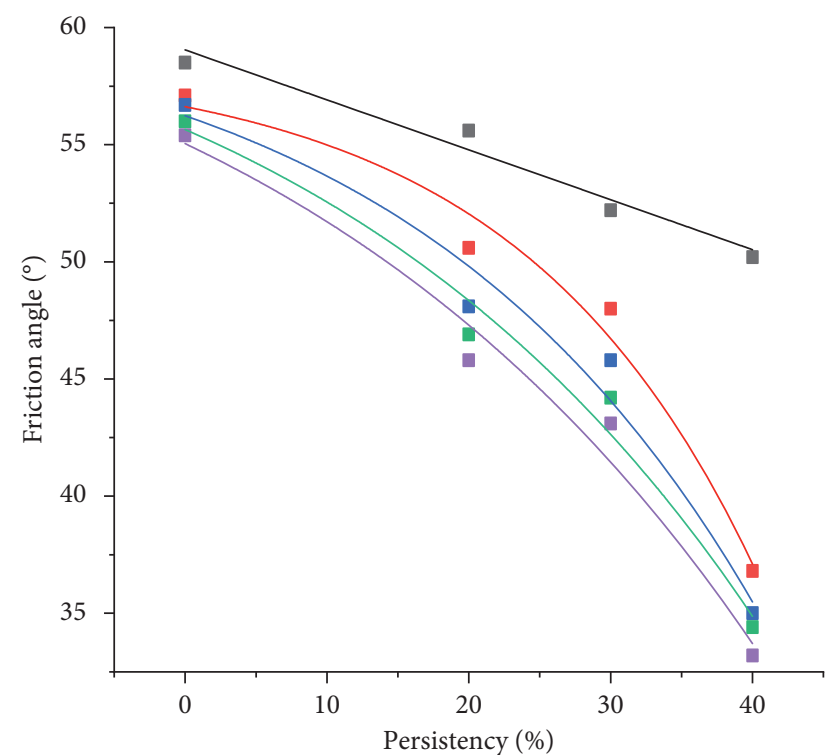

Freeze-thaw cycles

- 0 (test data)

- 10 (test data)

- 20 (test data)

- 30 (test data)

- 40 (test data)
_ 0 (fitting curve)

_ $20 \%$ (fitting curve)

_- 30\% (fitting curve)

__ $40 \%$ (fitting curve)

(b) 
$30 \%$, and $40 \%$ decreased by $47.75 \%, 52.52 \%$, and $69.54 \%$, and the friction angles decreased by $16.27 \%, 21.93 \%$, and $43.84 \%$. Moreover, the similar regularity of variation was also shown by specimens with other freezing-thawing cycles. Therefore, cohesion decreases sharply for joint persistency from 0 to $20 \%$ under freezing-thawing cycles. In addition, cohesion decreased slowly as the persistency increases. However, the friction angle decreases slightly and then decreases sharply with joint persistency increase, and friction angle decreases more significantly with persistency variation. Consequently, friction angle is the dominant factor that controls shear strength when the number of freezing-thawing cycles is constant.

Therefore, the freezing-thawing cycles and the joint persistency have significant effects on the degradation of joint shear strength parameters, yet the variation laws are quite different. The increase of the joint persistency causes the freezing-thawing cycle to promote deterioration of the joint strength. Furthermore, the freezing-thawing cycle accelerates the expansion of the joint, resulting in significant decrease in the joint shear strength.

\section{Conclusions}

(1) The damage of shear strength mainly generates in the initial stage of the freezing-thawing cycle, while the shear strength decreases slightly in the late stage. Freezing-thawing cycles have less effect on the shear strength of joint specimens with low persistency. However, it has a greater effect on joint specimens with large persistency. Moreover, the freezingthawing cycle will promote roughness deterioration when the joint persistency increases.

(2) The peak shear strength of the intact specimen decreases linearly with the freezing-thawing cycle increase, and the decrease is small before and after the freezing-thawing cycles. The joint specimen decreases nonlinearly with the increase of freezing-thawing cycles, and shear strength decreased significantly before and after freezing-thawing cycles.

(3) Both the freezing-thawing cycles and the joint persistency have significant effects on the degradation of the joint shear strength parameters, yet the variation laws of the two factors on joint cohesion and friction angle are quite different. The increase of the joint persistency causes the freezingthawing cycle to promote the deterioration of the joint strength. Furthermore, the freezing-thawing cycle accelerates the expansion of the joint, resulting in a significant decrease in joint shear strength.

\section{Data Availability}

The data used to support the findings of this study are available from the corresponding author upon request.

\section{Conflicts of Interest}

The authors declare no conflicts of interest.

\section{Acknowledgments}

This study received funding from the project (51774322) supported by the National Natural Science Foundation of China, project (2018JJ2500) supported by the Hunan Provincial Natural Science Foundation of China, and project (2018zzts209) supported by the Fundamental Research Funds for the Central Universities of Central South University. The authors wish to acknowledge these supports.

\section{References}

[1] Y. Shen, G. Yang, L. Tang, and X. Wang, "Development trend and statistics of the field of geotechnical mechanics and engineering in cold regions funded by NSFC during 2006-2015," Journal of Glaciology \& Geocryology, vol. 37, 2015.

[2] C. Pratt, R. Macciotta, and M. Hendry, "Quantitative relationship between weather seasonality and rock fall occurrences north of Hope, BC, Canada," Bulletin of Engineering Geology and the Environment, vol. 78, no. 5, pp. 3239-3251, 2019.

[3] X. Yang, A. Jiang, and M. Li, "Experimental investigation of the time-dependent behavior of quartz sandstone and quartzite under the combined effects of chemical erosion and freeze-thaw cycles," Cold Regions Science and Technology, vol. 161, pp. 51-62, 2019.

[4] H. Lin, X. Ding, R. Yong, W. Xu, and S. Du, "Effect of nonpersistent joints distribution on shear behavior," Comptes Rendus Mécanique, vol. 347, no. 6, pp. 477-489, 2019.

[5] M. Bahaaddini, G. Sharrock, and B. K. Hebblewhite, "Numerical investigation of the effect of joint geometrical parameters on the mechanical properties of a non-persistent jointed rock mass under uniaxial compression," Computers and Geotechnics, vol. 49, no. 20, pp. 206-225, 2013.

[6] W. Yang, G. Li, P. Ranjith, and L. Fang, "An experimental study of mechanical behavior of brittle rock-like specimens with multi-non-persistent joints under uniaxial compression and damage analysis," International Journal of Damage Mechanics, vol. 28, no. 10, pp. 1490-1522, 2019.

[7] C. Zhang, C. Pu, R. Cao, T. Jiang, and G. Huang, "The stability and roof-support optimization of roadways passing through unfavorable geological bodies using advanced detection and monitoring methods, among others, in the Sanmenxia Bauxite Mine in China's Henan Province," Bulletin of Engineering Geology and the Environment, vol. 78, no. 7, pp. 5087-5099, 2019.

[8] Y. Chen and H. Lin, "Consistency analysis of Hoek-Brown and equivalent Mohr-Coulomb parameters in calculating slope safety factor," Bulletin of Engineering Geology and the Environment, vol. 78, no. 6, pp. 4349-4361, 2019.

[9] H. Lin, W. Xiong, Z. Xiong, and F. Gong, "Three-dimensional effects in a flattened Brazilian disk test," International Journal of Rock Mechanics and Mining Sciences, vol. 74, pp. 10-14, 2015.

[10] R. Yong, J. Ye, S.-G. Du, H. Zhang, L. Gu, and H. Lin, “A dice similarity measure for TBM penetrability classification in hard rock condition with the intuitionistic fuzzy information of rock mass properties," European Journal of Environmental and Civil Engineering, vol. 24, pp. 1-16, 2019. 
[11] J. Shen and R. Jimenez, "Predicting the shear strength parameters of sandstone using genetic programming," Bulletin of Engineering Geology and the Environment, vol. 77, pp. 1-16, 2018.

[12] N. Xu, F. Dai, Z. Zhou, P. Jiang, and T. Zhao, "Microseismicity and its time-frequency characteristics of the left bank slope at the Jinping first-stage hydropower station during reservoir impoundment," Environmental Earth Sciences, vol. 75, no. 7, p. $608,2016$.

[13] F. Dai, Y. Xu, T. Zhao, N.-w. Xu, and Y. Liu, "Loading-ratedependent progressive fracturing of cracked chevron-notched Brazilian disc specimens in split Hopkinson pressure bar tests," International Journal of Rock Mechanics and Mining Sciences, vol. 88, no. 2, pp. 49-60, 2016.

[14] Y.-J. Shen, G.-S. Yang, H.-W. Huang, T.-L. Rong, and H.-L. Jia, "The impact of environmental temperature change on the interior temperature of quasi-sandstone in cold region: experiment and numerical simulation," Engineering Geology, vol. 239, pp. 241-253, 2018.

[15] G. Khanlari, R. Z. Sahamieh, and Y. Abdilor, "The effect of freeze-thaw cycles on physical and mechanical properties of Upper Red Formation sandstones, central part of Iran," Arabian Journal of Geosciences, vol. 8, no. 8, pp. 5991-6001, 2015.

[16] J. Martínez-Martínez, D. Benavente, M. Gomez-Heras, L. Marco-Castaño, and M. Á. García-del-Cura, "Non-linear decay of building stones during freeze-thaw weathering processes," Construction and Building Materials, vol. 38, no. 1, pp. 443-454, 2013.

[17] M. H. Ghobadi and R. Babazadeh, "Experimental studies on the effects of cyclic freezing-thawing, salt crystallization, and thermal shock on the physical and mechanical characteristics of selected sandstones," Rock Mechanics and Rock Engineering, vol. 48, no. 3, pp. 1001-1016, 2015.

[18] A. Momeni, Y. Abdilor, G. R. Khanlari, M. Heidari, and A. A. Sepahi, "The effect of freeze-thaw cycles on physical and mechanical properties of granitoid hard rocks," Bulletin of Engineering Geology and the Environment, vol. 75, no. 4, pp. 1649-1656, 2016.

[19] Y. Jin, C. Xu, L. Hong, J. W. Zhou, and Y. Y. Cai, "Effect of freeze-thaw cycles on mechanical properties and permeability of red sandstone under triaxial compression," Journal of Mountain Science, vol. 12, no. 1, pp. 218-231, 2015.

[20] Q. Liu, S. Huang, Y. Kang, and X. Hunag, "Fatigue damage model and evaluation index for rock mass under freezingthawing cycles," Chinese Journal of Rock Mechanics and Engineering, vol. 34, no. 6, pp. 1116-1127, 2015.

[21] Y. Lu, X. Li, and A. Chan, "Damage constitutive model of single flaw sandstone under freeze-thaw and load," Cold Regions Science and Technology, vol. 159, pp. 20-28, 2019.

[22] W. Fang, N. Jiang, and X. Luo, "Establishment of damage statistical constitutive model of loaded rock and method for determining its parameters under freeze-thaw condition," Cold Regions Science and Technology, vol. 160, pp. 31-38, 2019.

[23] Y. Wang, H. Lin, Y. Zhao, X. Li, P. Guo, and Y. Liu, "Analysis of fracturing characteristics of unconfined rock plate under edge-on impact loading," European Journal of Environmental and Civil Engineering, vol. 23, pp. 1-16, 2019.

[24] H. Lin, S. Xie, R. Yong, Y. Chen, and S. Du, "An empirical statistical constitutive relationship for rock joint shearing considering scale effect," Comptes Rendus Mécanique, vol. 347, no. 8, pp. 561-575, 2019.

[25] P. Štefane, S. Naib, S. Hertelé, W. De Waele, and N. Gubeljak, "Crack tip constraint analysis in welded joints with pronounced strength and toughness heterogeneity," Theoretical and Applied Fracture Mechanics, vol. 103, Article ID 102293, 2019.

[26] Y. Zhao, Y. Wang, W. Wang, L. Tang, Q. Liu, and G. Cheng, "Modeling of rheological fracture behavior of rock cracks subjected to hydraulic pressure and far field stresses," Theoretical and Applied Fracture Mechanics, vol. 101, pp. 59-66, 2019.

[27] Y. Zhao, L. Zhang, W. Wang, J. Tang, H. Lin, and W. Wan, "Transient pulse test and morphological analysis of single rock fractures," International Journal of Rock Mechanics and Mining Sciences, vol. 91, pp. 139-154, 2017.

[28] M. Wang, P. Cao, and Y. Chen, "Anisotropy of rock profile JRC values and its empirical formula: a case study on yellow rust granite," Geotechnical and Geological Engineering, vol. 35, no. 4, pp. 1645-1655, 2017.

[29] K. Zhang, P. Cao, G. Ma, W. Wang, W. Fan, and K. Li, "Strength, fragmentation and fractal properties of mixed flaws," Acta Geotechnica, vol. 11, no. 4, pp. 901-912, 2016.

[30] Q. Lin, P. Cao, and R. Cao, "Experimental investigation of jointed rock breaking under a disc cutter with different confining stresses," Comptes Rendus Mécanique, vol. 346, no. 9, pp. 833-843, 2018.

[31] R. Sahlaoui, K. Sab, and J.-V. Heck, "Yield strength of masonry-like structures containing thin adhesive joints: 3D or 2D-interface model for the joints?," Comptes Rendus Mécanique, vol. 339, no. 6, pp. 432-438, 2011.

[32] M. Heshmati, R. Haghani, M. Al-Emrani, and A. André, "On the strength prediction of adhesively bonded FRP-steel joints using cohesive zone modelling," Theoretical and Applied Fracture Mechanics, vol. 93, pp. 64-78, 2018.

[33] M. Krautblatter, D. Funk, and F. K. Günzel, "Why permafrost rocks become unstable: a rock-ice-mechanical model in time and space," Earth Surface Processes and Landforms, vol. 38, no. 8, pp. 876-887, 2013.

[34] J.-Q. Mu, X.-J. Pei, R.-Q. Huang, N. Rengers, and X.-Q. Zou, "Degradation characteristics of shear strength of joints in three rock types due to cyclic freezing and thawing," Cold Regions Science and Technology, vol. 138, pp. 91-97, 2017.

[35] M. C. R. Davies, O. Hamza, and C. Harris, "The effect of rise in mean annual temperature on the stability of rock slopes containing ice-filled discontinuities," Permafrost and Periglacial Processes, vol. 12, no. 1, pp. 137-144, 2001.

[36] H. Lin, H. Yang, Y. Wang, Y. Zhao, and R. Cao, "Determination of the stress field and crack initiation angle of an open flaw tip under uniaxial compression," Theoretical and Applied Fracture Mechanics, vol. 104, Article ID 102358, , 2019.

[37] X. Fan, H. Lin, H. Lai, R. Cao, and J. Liu, "Numerical analysis of the compressive and shear failure behavior of rock containing multi-intermittent joints," Comptes Rendus Mécanique, vol. 347, no. 1, pp. 33-48, 2019.

[38] Y. Wang, P. Guo, X. Li, H. Lin, Y. Liu, and H. Yuan, "Behavior of fiber-reinforced and lime-stabilized clayey soil in triaxial tests," Applied Sciences, vol. 9, no. 5, p. 900, 2019.

[39] W. Yang, Q. Zhang, P. G. Ranjith et al., "A damage mechanical model applied to analysis of mechanical properties of jointed rock masses," Tunnelling and Underground Space Technology, vol. 84, pp. 113-128, 2019.

[40] Y. Zhao, Y. Wang, W. Wang, W. Wan, and J. Tang, "Modeling of non-linear rheological behavior of hard rock using triaxial rheological experiment," International Journal of Rock Mechanics and Mining Sciences, vol. 93, pp. 66-75, 2017.

[41] Y. Zhao, L. Zhang, W. Wang et al., "Creep behavior of intact and cracked limestone under multi-level loading and unloading cycles," Rock Mechanics \& Rock Engineering, vol. 50, no. 6, pp. 1-16, 2017. 


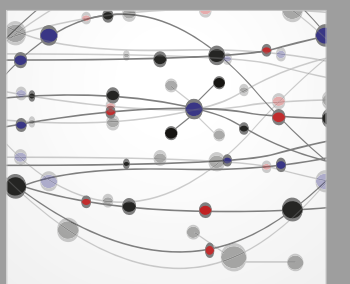

The Scientific World Journal
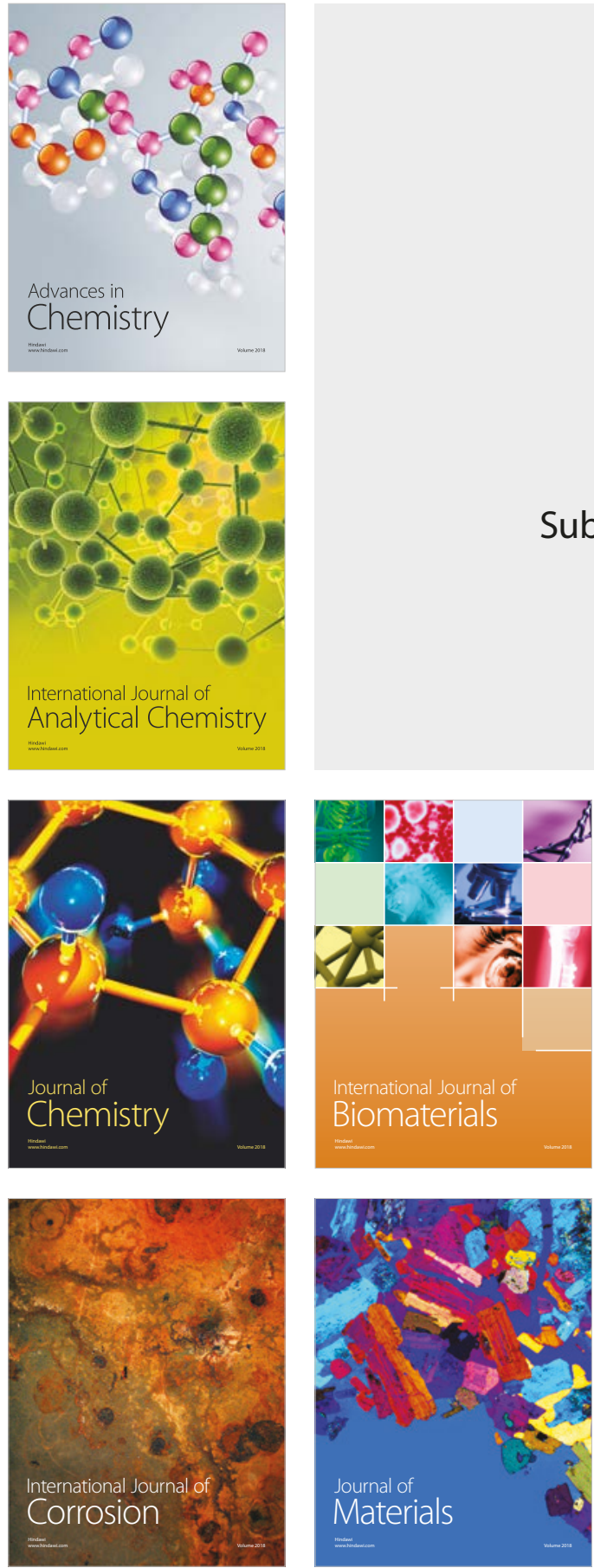

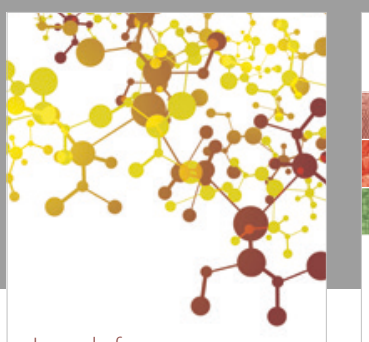

Journal of

Applied Chemistry
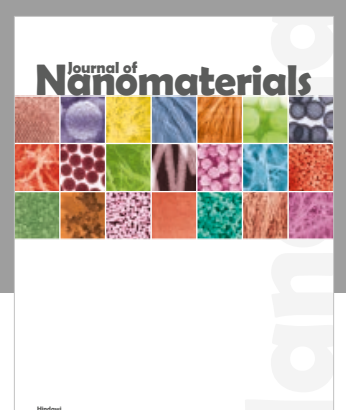

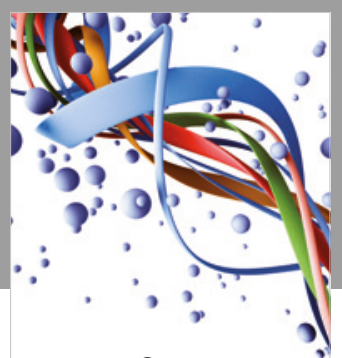

Scientifica

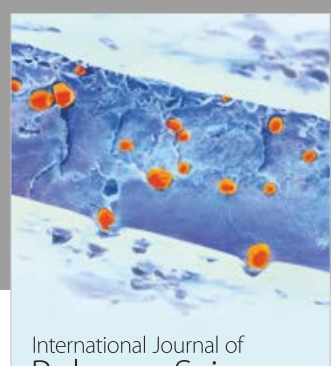

Polymer Science

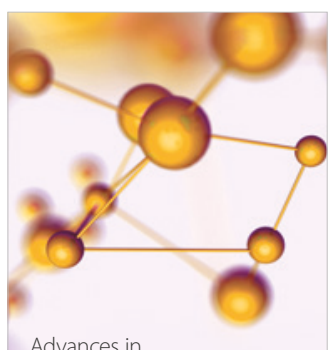

Physical Chemistry
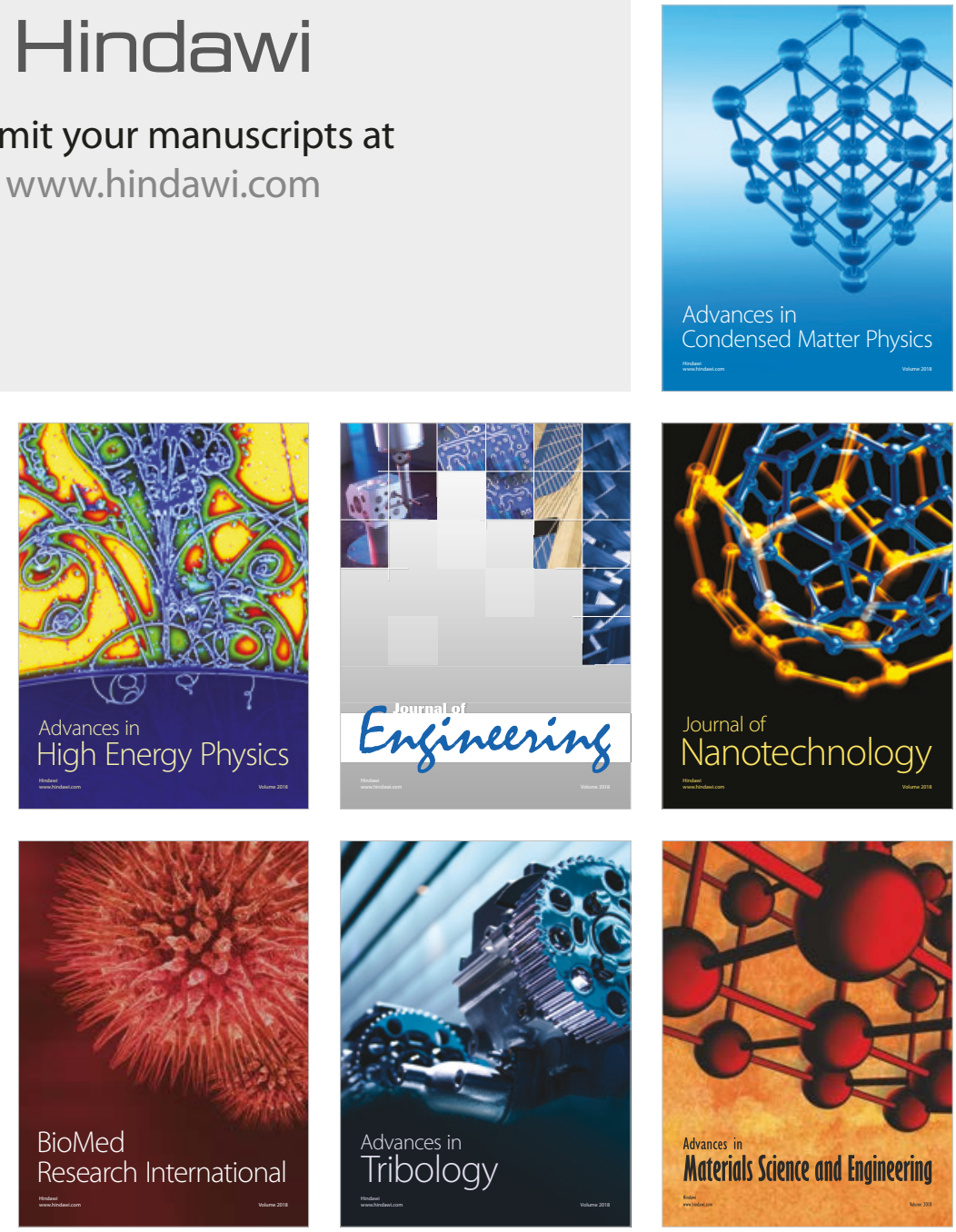